\title{
Cole-Carpenter syndrome
}

INSERM

\section{Source}

INSERM. (1999). Orphanet: an online rare disease and orphan drug data base. Cole-

Carpenter syndrome. ORPHA:2050

Cole-Carpenter syndrome is an extremely rare form of bone dysplasia characterized by the features of osteogenesis imperfecta such as bone fragility associated with multiple fractures, bone deformities (metaphyseal irregularities and bowing of the long bones) and blue sclera, in association with growth failure, craniosynostosis, hydrocephalus, ocular proptosis, and distinctive facial features (e.g. frontal bossing, midface hypoplasia, and micrognathia). 